«Университет управления ТИСБИ», 423800, Россия, г. Набережные Челны, ул. Татарстан, дом 10

Овчинников Юрий Дмитриевич - кандидат технических наук, доцент, Федеральное государственное бюджетное образовательное учреждение высшего образования «Кубанский государственный университет физической культуры, спорта и туризма», г. Краснодар, Россия, 350015, ул. Буденного, дом 161

Головко Петр Вячеславович - студент, Федеральное государственное бюджетное образовательное учреждение высшего образования «Кубанский государственныи университет физической культуры, спорта и туризма», г. Краснодар, Россия, 350015, ул. Буденного, дом 161

DOI 10.14526/02_2018_309

УДК 796.83

ББК 75.1

\title{
РАЗВИТИЕ КООРДИНАЦИОННЫХ СПОСОБНОСТЕЙ В ПРОЦЕССЕ СПОРТИВНОЙ ТРЕНИРОВКИ ЗАНИМАЮЩИХСЯ СПОРТИВНЫМИ ВИДАМИ ЕДИНОБОРСТВ С ПРИМЕНЕНИЕМ СПЕЦИФИЧЕСКИХ ДВИГАТЕЛЬНЫХ ТРЕНИРОВОЧНЫХ ЗАДАНИЙ
}

\author{
Миниханов В. . $^{1}$ \\ ${ }^{1}$ Федеральное государственное бюджетное образовательное учреждение выстего \\ образования «Российский университет транспорта (МИИТ)» \\ Россия, Москва,vlminih@mail.ru
}

\begin{abstract}
Аннотация. Высокий уровень развития координационных способностей необходим для спортсменов практически во всех видах прикладных единоборств, поскольку высокие возможности управления своими координационными способностями позволяют рационально проводить технические действия и определяют спортивный результат. От развития координачии в решающей степени зависит успешность обучения новым двигательным действиям и совершенствования их усвоенных форм, проявляюшихся во всех сферах двигательной деятельности. Материалы. Разработка и экспериментальное обоснование методики развития координационных способностей в прочессе спортивной тренировки занимающихся спортивными видами единоборств с применением специфических двигательных тренировочных заданий. Методологической основой проведения работьл явилось построение движений в соответствии с концепцией многоуровневой системь управления произвольными движениями Н.А. Бернштейна. Методы исследования: анализ и обобщение научной литературы, теоретический анализ и обобщение многолетнего опыта спортивной тренировки и работы со студентами сборных команд в качестве стариего тренера Российского университета транспорта по видам спортивных единоборств. Результаты. $B$ результате теоретического и экспериментального исследования разработана методика развития координационных способностей в процессе спортивной тренировки занимающихся рукопашным боем, самбо, дзюдо с применением специифических двигательных тренировочных заданий. Содержание предложенной в работе методики развития координачионных способностей предполагает пошаговую педагогическую технологию, включающую: определение понятия координачионной способности,
\end{abstract}


направленность педагогических воздействий, методы, средства, методические приёмьи и параметры тренировочной нагрузки. Эффективность методики проверена $в$ педагогическом эксперименте. Результать предложенной методики развития координационных способностей могут быть использованы в педагогическом образовании на кафедрах спортивного совершенствования и физического воспитания в прочессе учебных занятий со спортсменами педагогических вузов, культивирующих прикладные видь спортивных единоборств. Заключение. Разработанная методика развития координационных способностей $с$ применением специифических двигательных тренировочных заданий обусловила улучшение координаџионной способности, влияющих на показатели соревновательной деятельности и спортивного мастерства.

Ключевые слова: развитие, координационные способности, спортивные единоборства, тренировочное задание.

Для цитирования: Миниханов В.А. Развитие координационных способностей в процессе спортивной тренировки занимающихся спортивными видами единоборств с применением специфических двигательных тренировочных заданий. Педагогико-психологические $u$ медико-биологические проблемы физической культуры и спорта. 2018; 13(2): 63-70. DOI 10.14526/02_2018_309

\title{
COORDINATING SKILLS DEVELOPMENT DURING SPORTS TRAINING PROCESS OF PEOPLE GOING IN FOR COMBAT SPORTS USING SPECIFIC MOTOR TRAINING TASKS
}

\author{
Minikhanov $V$. A. $^{1}$ \\ ${ }^{1}$ Federal State Budgetary Educational Establishment of Higher Education "Russian University of \\ Transport (MIET)" \\ Russia,Moscow,vlminih@mail.ru
}

Annotation. High development level of coordinating skills is necessary for sportsmen almost in all kinds of applied combat sports, as developed abilities of own coordinating skills control help to fulfill rationally technical actions and condition sports result. Success of teaching new motor actions and their mastered forms, demonstrated in all spheres of motor activity, depends on coordination development. Materials. The methodology of coordinating skills development creation and experimental substantiation during sports training process of people going in for combat sports using specific motor training tasks. Methodological basis of the research was movements organization in accordance with the concept of multi-level system of voluntary movements management (N.A. Bernshteyn). Research methods: scientific literature analysis and summarizing, theoretical analysis and summarizing of a long-term experience of sports training and work with students of combat sports national teams senior trainer at Russian University of Transport. Results. As a result of theoretical and experimental research methodology is created of coordinating skills development during sports training of those, who go in for hand-to-hand combat, sambo, judo, using specific motor training tasks. The content of the offered in work methodology of coordinating skills development provides step by step pedagogical technology, which includes the following: definition of "coordinating ability" notion, orientation of pedagogical influences, methods, means, methodological techniques and parameters of a training load. The effectiveness of the methodology is checked during the pedagogical experiment. The results of the offered methodology of coordinating skills development can be used in pedagogical education at sports improvement and physical upbringing department during the lessons with sportsmen from pedagogical higher educational establishments, who cultivate the applied kinds of combat sports. Conclusion. The created methodology of coordinating skills development, using specific motor training tasks, 
conditioned coordinating skills improvement, which influence competitive activity and sportsmanship indices.

Keywords: development, coordinating skills, combat sports, training task.

For citations: Minikhanov V.A. Coordinating skills development during sports training process of people going in for combat sports using specific motor training tasks. The Russian Journal of Physical Education and Sport (Pedagogico-Phycological and Medico-Biological Problems of Physical Culture and Sports). 2018; 13(2): 63-70. DOI 10.14526/02_2018_309

\section{ВВЕДЕНИЕ}

Современная теория и практика педагогического образования, физического воспитания и спортивной тренировки относит координационные способности к одним из наименее изученных и рассматривает их как один из важных разделов, представляющих сложный по своей структуре процесс, обеспечиваемый функциями различных систем организма. Высокий уровень развития координационных способностей необходим для спортсменов практически во всех видах прикладных единоборств, поскольку высокие возможности управления своими координационными способностями позволяют рационально проводить технические действия и определяют спортивный результат. От развития координации в решающей степени зависит успешность обучения новым двигательным действиям и совершенствования их усвоенных форм, проявляющихся во всех сферах двигательной деятельности $[5,6,7,10]$.

Н.А. Бернштейн под координацией движений понимает следующее: «это есть преодоление избыточных степеней свободы двигающегося органа, иными словами, превращение последнего в управляемую систему» [2, с. 96].

Под влиянием тренировки способность двигательной координации улучшается. Разработка методики развития специфических двигательнокоординационных способностей в процессе учебных занятий спортивными видами единоборств основывается на методологии и теории развития кондиционных возможностей,

закономерностях физического воспитания и спортивной тренировки $[1,4,10,11,12]$.

Цель: разработать методику развития координационных способностей занимающихся спортивными видами единоборств.

Задача:

специфические

разработать двигательные тренировочные задания, направленные на развитие координационных способностей занимающихся спортивными видами единоборств.

\section{МАТЕРИАЛЫ И МЕТОДЫ}

Методы и организация

исследования. Реализация цели

исследования осуществлялась с использованием методов анализа педагогической л литературы, анкетирования, математической статистики (двухвыборочный $\mathrm{t}$-тест Стьюдента для независимой выборки), интерпретации. Расчеты проводились по пакету анализа Microsoft Excel статистической обработки первичных данных.

\section{РЕЗУЛЬТАТЫ}

\section{ИССЛЕДОВАНИЯ ОБСУЖДЕНИЕ \\ И \\ ИX}

Развитие координационных способностей в процессе спортивной тренировки с применением специфических двигательных тренировочных заданий предполагает применение определённой методики. Методика - совокупность методов, средств и методических приёмов, направленных на достижение определенных результатов в спортивной тренировке.

Методика

координационных заключается - в подборе тренировочных 
заданий. Г.Н. Германов предложил соотношение структурных элементов тренировочного задания, включающего цель; задачи тренировочного задания, направленные на обучение, совершенствование технико-тактического мастерства и развитие физической подготовленности. Тренировочное задание должно включать технологическую форму организации с учетом параметров тренировочной нагрузки. Конечным результатом воздействия является тренировочный эффект [4].

Содержание предложенной методики развития координационных способностей в процессе учебных занятий спортивными видами единоборств предполагает пошаговую педагогическую технологию, включающую опору на определение понятия координационных способностей, направленность педагогических воздействий, методы, средства, (тренировочные задания), методические приёмы и параметры тренировочной нагрузки.

Раскроем содержание пошаговой педагогической технологии развития координационных способностей в процессе учебных занятий спортивными видами единоборств на примере развития сохранения положения тела, удержания равновесия, проявляющейся в условиях соревновательной деятельности в рукопашном бое, самбо, дзюдо, кикбоксинге и др.

1. Определение понятия. Удержание равновесия при выполнении двигательных действий - это способность к устойчивому сохранению положения тела и удержанию равновесия как параметра координации, которая определяется умением сохранять устойчивость тела и его отдельных звеньев в статических, динамических действиях или поддерживать балансировку стоя на обеих ногах, на одной ноге, колене [10].

Специфические двигательные координационные способности занимающихся спортивными видами единоборств - это достигнутые в результате приобретенных умений и навыков, обусловленных требованиями соревновательной деятельности, проявляющиеся в своевременности, точности, упорядоченности и согласованности в пространстве, во времени движений отдельных частей тела, целесообразности построения целостных двигательных действий, быстроте перестроения движений в соответствии с меняющимися динамическими ситуациями, возникшими в ходе спортивного поединка $[8$, c. 60$]$.

2.

Направленность педагогических воздействий заключается в развитии отдельных параметров координационных способностей, которые обусловлены требованиями соревновательной деятельности. Теоретический анализ $[8,10,11,12]$ позволил выделить 26 параметров координационных способностей, к которым относят точность, быстроту обучения двигательным действиям, сохранение положения тела, удержание равновесия и др.

\section{3. Методы развития отдельных} параметров координационных способностей достаточно многообразны. Перечислим, некоторые из них:

- переменного упражнения - метод строго и не строго регламентированного варьирования физической нагрузки: активные, пассивные и комбинированные, направленные на адекватное раздражение вестибулярного аппарата [7, с. 196, 10, с. 166-168];

- направленного сопряжения, предполагающего развитие двигательных координационных способностей и выполнение отдельных фаз техникотактического действия $[1,4,11,13,14]$; 8].

- соревновательный и игровой $[5$,

\section{4. Средства развития} координационных способностей специфической направленности педагогических воздействий предполагают тренировочных заданий. Методика 
формирования

равновесия

предусматривает подбор тренировочных заданий. Тренировочное задание - это исполнительная форма целевой двигательной задачи технического действия для достижения должных проявлений тренировочного эффекта. Тренировочное задание является минимальной двигательной единицей учебного процесса и имеет структурнофункциональное сходство с единицами более высоких уровней, с занятием, микроциклом [4, 7, с. 196].

Для занимающихся спортивными видами единоборств в целях развития равновесия рекомендуются следующие специальные тренировочные задания:

$$
\text { - после раздражения }
$$

вестибулярного аппарата применять кувырки, бой с тенью, вращения туловища в различных плоскостях в прыжке на $180^{\circ}$, $360^{\circ}$;

- поддержание равновесия в статических и динамических позах в условиях двигательных помех, создаваемых предшествующими или сопутствующими вращательными воздействиями соперника, стремительным наступлением с нанесением ударов руками и ногами;

- учебные поединки, в ходе которых спортсмен приобретает навыки способов перемещения общего центра масс и отдельных звеньев тела с изменением ритмовых параметров движений в условиях нарастающего утомления;

- постановка различных заданий партнеру. Например, партнер воспроизводит определенные положения тела, осуществляя технические действия, с различной скоростью и силой в ответ на действия, облегчающие или затрудняющие выполнение заданных движений;

- рекомендуются избирательное воздействие на функцию вестибулярного аппарата средствами игр в теснении, тренировочных сближающих и контрастных заданий, применение спортивных тренажеров, качелей, центрифуг [8, с 18].
Примерный комплекс упражнений на сохранение равновесия на примере каратэ рекомендует Ю.В. Филиппова с соавторами. Комплекс включает хождение по ограниченной плоскости с поворотами, не нарушая равновесие, стоя на одной ноге при сбивающих факторах: вращениях головы, поворотов туловища с открытыми и закрытыми глазами [14].

\section{5. Методические приёмы.} Методический приём - это способ воздействия, который осуществляется в некоторых конкретных условиях при решении частных задач. К ним относятся методические приёмы строго заданных частных характеристик освоенных двигательных атакующих и защитных тактических двигательных действий $[10$, с. 175].

6. Параметры физической тренировочной нагрузки. Физическая нагрузка в тренировочном задании характеризуется следующими параметрами: характером упражнений (по относительному количеству мышц, вовлечённых в физическую работу: глобального, регионального и локального воздействия), интенсивностью и продолжительностью физической работы, продолжительностью и характером интервалов отдыха между отдельными тренировочными заданиями и сериями тренировочных заданий $[5,6,7,8,9,12$, 13].

$\begin{array}{cr}\text { Данная методика } & \text { проверена в } \\ \text { формирующем } & \text { педагогическом }\end{array}$ эксперименте, который был проведен на базе Российского университета транспорта. Выявленные фактические значения координационных способностей до эксперимента в обеих группах по всем показателям были статистически недостоверными ( $\mathrm{P}>0,05-0,01)$.

Контрольная группа состояла из студентов, занимающихся спортивными видами единоборств, в ней проводились занятия по общепринятой методике тренировки. В состав опытной группы также вошли спортсмены-студенты, занимающиеся спортивными видами 
единоборств. В этой группе учебнотренировочная работа проводилась по разработанной нами методике.

В таблице представлены результаты показателей подготовленности студентов контрольной и опытной групп после формирующего педагогического эксперимента. Достоверно улучшились показатели специфических координационных способностей, надёжности атаки, защиты в положении борьбы стоя и спортивное мастерство

Позитивная динамика показателей подготовленности у спортсменовстудентов в процессе учебных занятий спортивными видами единоборств в опытной группе обусловлена применением разработанной методики. Результаты формирующего педагогического эксперимента свидетельствуют об эффективности предложенной методики развития координационных способностей, повлиявших на улучшение показателей соревновательной деятельности и спортивного мастерства.

\section{ЗАКЛЮЧЕНИЕ}

Современная теория и практика педагогического образования и спортивной тренировки относит координационные способности к одним из наименее изученных двигательных качеств.

\section{Предложенная}

методика пошагового развития двигательнокоординационных способностей в процессе учебных занятий спортивными видами единоборств включает: опору на определение понятия, направленность педагогических воздействий, методы, средства, методические приёмы и параметры тренировочной физической нагрузки.

$\begin{array}{ll}\text { Разработанная } & \text { методика с } \\ \text { применением } & \text { специфических }\end{array}$
двигательных тренировочных заданий обусловила улучшение координационной способностей, влияющих на показатели соревновательной деятельности и спортивного мастерства.

\section{Список литературы}

1. Акопян А.О., Кулагина Л.А. Реакция антиципации в боксе. Вестник спортивной науки. 2016; 6: 3-7.

2. Анцыперов В.В., Филлипов М.В. Особенности проявления координационных способностей при проведении технико-тактических действий в дзюдо. Современные проблемы науки и образования. 2014; 5. URL: http://www.scienceeducation.ru/ru/article/view?id=14606.

3. Бернштейн Н.А. Очерки по физиологии движений $и$ физиологии активности. М.: Медицина. 1966: 349.

4. Германов Г.Н., Цуканова Е.Г., Новикова А.А. Педагогическая технология пошаговой регламентации двигательных заданий, используемых в подготовке юных бегунов на средние дистанции. Ученые записки университета им. П.Ф. Лесгафта. 2011; 79(9): 50-58.

5. Горская И.Ю., Афанасьева И.В., Ревенко Е.M. Оиенка $и$ совершенствование координационных способностей у студентов. Омск: СибАДИ. 2014: 213.

6. Еганов А.В. Обоснование модели тренировки дзюдоистов на этапе максимальной реализации индивидуальных возможностей. Современные наукоемкие технологии. 2009; 5: 1921.

7. Еганов А.В. Теория и методика спортивной тренировки дзюдоистов. М.: Теория и практика физической культуры и спорта. 2014: 212.

8. Еганов А.В., Пакетин Д.А., Позняков Г.П. Теория и методика развития двигательнокоординационных способностей курсантовштурманов. Челябинск: ЧВВАКУШ. 2017: 228.

9. Еганов В.А., Миронов А.О., Олин С.В. Методика организации тренировочных заданий, связанных с проявлением координационных способностей, направленных на повышение эффективности выполнения надёжности защитных тактико-технических действий в прикладных видах единоборств. Ученые записки университета им. П.Ф. Лесгафта. 2011; 7(77): 63-68.

10. Колесник И.С., Кузнецов А.С., Петров А.Г. Теоретическое и методическое обоснование формирования равновесия как одной из ведущих двигательных координаций у боксеров. Педагогико-психологические и медикобиологические проблемь физической культуры $и$ cnopma. 2009; 2(11): 1-7. URL: http://www.journalscience.org/ru/article/407.html. 
11. Лях В.И. Важнейшие для различных видов спорта координационные способности и их значимость в техническом и технико-тактическом совершенствовании (по материалам зарубежной печати). Теория и практика физической культуры. 1988; 2: 56-59.

12. Назаренко А.С., Чинкин А.С. Влияние специфики двигательной деятельности на вестибулодвигательные и вестибулосенсорные реакции спортсменов. Педагогико-психологические и медико-биологические проблемы физической культуры и спорта. 2010; 3(16): 70-76. URL: http://www.journal-science.org/ru/article/384.html.

13. Струихин И.А., Миниханов В.А., Еганов В.А. Педагогическое обоснование направленности тренирующих воздействий на тактико-технические действия средствами двигательно-координационной подготовки в единоборстве киокусинкай. Современные проблемы науки и образования. 2015; 4: 158-163.

14. Филиппова Ю.В., Корженевкий А.Н., Кургузов Г.В. Адаптация единоборцев к соревновательным нагрузкам. Теория и практика физической культуры. 2004; 1: 44-49.

15. Kuznetsov A., Mutaeva I., Kuznetsova Z., 2017. Diagnostics of Functional State and Reserve Capacity of young Athletes' Organism. In Proceedings of the $5^{\text {th }}$ International Congress on Sport Sciences Research and Technology support. SCITEPRESS. P. 111-115 (Scopus).

\section{References}

1. Akopyan, A.O., Kulagina L.A. Anticipation reaction in boxing. Vestnik sportivnoj nauki $=$ Sports science bulletin. 2016; 6: 3-7 [In Russ., In Engl.].

2. Antsyperova V.V., Filippov M.V. The peculiarities of coordinating skills demonstration during technical-tactical actions fulfillment in judo. Sovremennye problem nauki I obrazovaniya. 2014; 5. URL: education.ru/ru/article/view?id=14606. http://www.science-

3. Bernshteyn N.A. Ocherki po fiziologii dvizhenij I fiziologii aktivnosti [Physiology of movements and physiology of activity essays]. Moscow: Medicine. 1966: 349.

4. Germanov G.N., Tsukanova E.G., Novikova A.A. Pedagogical technology of step by step regulation of motor tasks, used in training young average distances runners. Uchenye zapiski Universiteta imeni P.F. Lesgafta. 2011; 79(9): 50-58 [In Russ.].

5. Gorskaya I.Y., Afanaseva I.V., Revenko E.M. Ocenka I sovershenstvovanie koordinacionnyh sposobnostej u studentov [Students' coordinating skills estimation and development]. Omsk: Siberian State Automobile-Engineering Institute. 2014: 213.

6. Eganov A.V. The model of training substantiation among judoists at the stage of individual abilities maximum realization. Sovremennye naukoemkie tehnologii. 2009; 5: 19-21 [In Russ.].

7. Eganov A.V. Teoriya I metodika sportivnoj trenirovki dzyudoistov [Theory and methodology of sports training of judoists]. Moscow: Theory and practice of physical culture and sport. 2014: 212.

8. Eganov A.V., Paketin D.A., Poznyakov G.P. Teoriya I metodika razvitiya dvigatel'nokoordinatsionnyh sposobnostej kursantov - shturmanov [Theory and methodology of motor-coordinating skills development among cadets- pilots]. Chelyabinsk: Chelyabinsk Higher Military Aviation Red Banner Order College of Pilots. 2017: 228.

9. Eganov V.A., Mironov A.O., Olin S.V. Methodology of training lessons organization, connected with coordinating skills demonstration, directed at effectiveness increase of defensive tacticaltechnical actions reliability fulfillment in applied combat sports. Uchenye zapiski Universiteta imeni P.F. Lesgafta. 2011; 7(77): 63-68 [In Russ.].

10. Kolesnik I.S., Kuznetsov A.S., Petrov A.G. Theoretical and methodical substantiation of balance formation as one of the leading motor coordinations among boxers. Pedagogikopsihologicheskie I mediko-biologicheskie problemy fizicheskoj kul'tury I sporta = Pedagogicopsychological and medico-biological problems of physical culture and sports. 2009; 2(11): 1-7. URL: http://www.journal-science.org/ru/article/407.html [In Russ., In Engl.].

11. Lyakh V.I. The most important for different kinds of sport coordinating skills and their value in technical and technical-tactical development (according to the materials of foreign literature). Teoriya I praktika fizicheskoj kul'tury = Theory and practice of physical culture. 1988; 2: 56-59 [In Russ., In Engl.].

12. Nazarenko A.S., Chinkin A.S. The specificity of motor activity influence on vestibularmotor and vestibular-sensory reactions of sportsmen. Pedagogiko-psihologicheskie I mediko-biologicheskie problemy fizicheskoj kul'tury I sporta = Pedagogicopsychological and medico-biological problems of physical culture and sports. 2010; 3(16): 70-76. URL: http://www.journal-science.org/ru/article/384.html. [In Russ., In Engl.].

13. Struikhin I.A., Minikhanov V.A., Eganov V.A. Pedagogical substantiation of the training influences orientation to tactical-technical actions by means of motor-coordinating training in Kyokushinkai. Sovremennye problem nauki I obrazovaniya. 2015; 4: 158-163 [In Russ.].

14. Filippova Y.V., Korzhenevskiy A.N., Kurguzov G.V. Adaptation of combatants to competitive loads. Teoriya I praktika fizicheskoj kul'tury = Theory and practice of physical culture. 2004; 1: 44-49 [In Russ., In Engl.].

15. Kuznetsov A., Mutaeva I., Kuznetsova Z., 2017. Diagnostics of Functional State and Reserve Capacity of young Athletes' Organism. In Proceedings of the $5^{\text {th }}$ International Congress on Sport Sciences Research and Technology support. SCITEPRESS. P. 111-115 (Scopus). 
Таблица - Показатели подготовленности спортсменов, занимающихся спортивными видами единоборств после формирующего педагогического эксперимента $(\overline{\mathrm{X}} \pm \mathrm{m})$

\begin{tabular}{|c|c|c|c|c|}
\hline \multirow[b]{2}{*}{ Показатели подготовленности } & \multicolumn{2}{|c|}{ После эксперимента } & \multirow[b]{2}{*}{$\mathrm{t}$} & \multirow[b]{2}{*}{$\mathrm{P}$} \\
\hline & $\begin{array}{c}\text { контрольная } \\
(\mathrm{n}=10)\end{array}$ & $\begin{array}{c}\text { опытная } \\
(\mathrm{n}=10)\end{array}$ & & \\
\hline $\begin{array}{c}\text { Специфические координационные } \\
\text { способности }\end{array}$ & $7,32 \pm 0,37$ & $8,91 \pm 0,23$ & $\begin{array}{c}- \\
3,58\end{array}$ & $<$ \\
\hline $\begin{array}{c}\text { Надёжность атаки в положении борьбы } \\
\text { стоя }\end{array}$ & $7,41 \pm 0,41$ & $8,26 \pm 0,35$ & $\begin{array}{c}- \\
1,99\end{array}$ & $<$ \\
\hline $\begin{array}{c}\text { Надёжность защиты в положении борьбы } \\
\text { стоя }\end{array}$ & $6,20 \pm 0,45$ & $7,86 \pm 0,42$ & - & $\begin{array}{c}< \\
0,05 \\
\end{array}$ \\
\hline Спортивное мастерство, усл. ед. & $42,23 \pm 4,3$ & $53,29 \pm 2,2$ & $\overline{-}$ & $<$ \\
\hline
\end{tabular}

Примечание: $\overline{\mathrm{X}} \pm \mathrm{m}$ - среднее значение \pm стандартная ошибка; <- различия между группами достоверны; двухвыборочный t-тест Стьюдента для независимой выборки; Р - уровень достоверности различий между группами

\title{
Подано: 13.05 .2018
}

Миниханов Владимир Ансарович - стариий преподаватель кафедры «Физическая культура», старший тренер МИИТ по видам спортивных единоборств, Федеральное государственное бюджетное образовательное учреждение высшего образования (ФГБОУ, ВО) «Российский университет транспорта (МИИТ)», 127994, Москва, ул. Образцова, д. 9, строение 9, Российский университет транспорта (МИИТ), $\underline{\text { e-mail vlminih@ mail.ru }}$

DOI 10.14526/02_2018_310

УДК 796.7.012.68

\section{УТОМЛЕНИЕ И ВОССТАНОВЛЕНИЕ КУРСАНТОВ ПРИ ИСПОЛЬЗОВАНИИ ПЕРЕМЕННОГО МЕТОДА НА ЗАНЯТИЯХ ОБРАЗОВАТЕЛЬНО- ТРЕНИРОВОЧНОЙ НАПРАВЛЕННОСТИ}

\author{
Пауесов C.A. ${ }^{1}$ \\ ${ }^{1}$ Пермский военный институт внутренних войск МВД России \\ Россия, г. Пермь, and1518@yandex.ru
}

Аннотация. Проблема утомления и восстановления при реализации физических $и$ психических нагрузок различной направленности считается актуальной общебиологической проблемой, представляет большой теоретический интерес и имеет ценное практическое значение для спортивной и профессиональной деятельности человека. Это позволило разработать программу развития общей и специальной выносливости курсантов на занятиях по физической подготовке с использованием переменного метода. Материалы. $B$ 